\title{
An IoT based Real-Time Monitoring of Water Quality System
}

\author{
Najiya Naj \\ ME student \\ Dept of Information Technology \\ Goa College of Engineering, \\ Goa, India.
}

\author{
Amogh Sanzgiri \\ Assistant Professor \\ Dept of Information Technology \\ Goa College of Engineering \\ Goa, India.
}

\begin{abstract}
With the emerging technologies and new generation, each field is developing gradually, like IoT, Artificial Intelligence, Big Data, Cloud Computing, etc. Currently, the Internet of Things (IoT) has become the pillar of all connected technologies, without which we can't imagine our single day. IoT is useful in every aspect of our life. Also, water is an essential component for all living beings, and monitoring of water quality and its parameter is a must to get safe water. The proposed model, water quality monitoring in Aquaculture based on IoT which is used to determine the different parameters of water like, $\mathrm{pH}$ value, turbidity, temperature, to detect the bad quality which may lead to any disease or adverse effect to a living being. So, it is crucial to detect the quality of water to have safe water for a healthy life. Traditional approaches include a manual collection of samples with complex methodology and ineffective because of timeconsuming, high cost, lack of real-time monitoring and testing is done later in the laboratory.
\end{abstract}

The presented paper is the evolution over the traditional approach which will determine the quality of water with aid of IoT in real-time. Internet of things is responsible for connecting various devices for sending and receiving data. The system used IoT that focuses on aquaculture species, and monitoring of water quality which helps the owner to determine the nature of water is good for the species or not. The system is like early detection of the quality and informs the owner to take required steps further. Different sensors are used to compute the data and send it to the cloud. The system is based on the ThingSpeak platform which is an IoT platform service that provides analysis, storage, and visualization of the data in the cloud through MATLAB. Later IFTTT applets are used to send the notification to the owner.

Keywords-IoT, Temperature sensor, Turbidity sensor, pH sensor, ThingSpeak, Water Quality.

\section{INTRODUCTION}

Aquaculture is also termed aquafarming, it is the process of growing, planting, taking care of aquatic life including fish, shellfish, and aquatic plants. Aquaculture is a large system that is divide into two parts, they are, Marine aquaculture and freshwater aquaculture. Marine aquaculture refers to the cultivation of fish that lives in the ocean and marine water. Freshwater aquaculture refers to the cultivation of fish that lives in freshwater like, lake, stream, or river. As the whole aquaculture will be a large water body, the proposed system is based on aqua scaping. Aqua scaping is the practice of creating a natural aquatic landscape in an aquarium, for example planted tanks. A planted tank is a planted aquarium in which one can plant the aquatic plants of their choice and put the aquatic fish over there. So, planted tank or planted aquarium is a customized aquarium to keep aquatic fish.

Our environment is full of development made by humans for the improvement of society. Monitoring the quality of the environment is an essential effort that permits the observation of different parameters which will help to control the environment downfall. Earlier, information is presented digitally to enhance the accuracy of the environment parameter monitoring and now data collecting and monitoring are based on online data analysis and cloud visualization. Water disease is one of the important parameters to be monitored, which may affect health badly. So, water monitoring is essential to have a stable life. Water monitoring includes detecting the feature, qualities, and different parameters of water and compared with some predefined values. For a more precise and authentic analysis of parameters, it is important to collect multiple samples, which will be inefficient in the case of the traditional approach. So, online monitoring with the help of IoT and cloud is done to get an accurate result and in real-time.

With the development of aquaculture industry, feature and quality of water like $\mathrm{pH}$, temperature, turbidity is becoming a most important factor to be measured. Water temperature is responsible for the feeding time and growth of fish. The quantity of dissolved oxygen is less in warm water than in cold water. Aquarium tanks need to be set up and maintained properly. The aquatic plants and animals present in the planted tank need to be taken care of. Their life may become short due to less water in the tank. The level of sunlight and carbon dioxide need to maintain for the proper growth of plants and fish. That's why it is crucial to observe the condition of water closely and properly.

\section{A. Disadvantage of Traditional approach}

- Collect sample manually.

- Complicated methodology.

- Time consuming.

- Low measurement precision.

- High cost.

- Lack of real-time monitoring

B. Advantage of Proposed system

- No need for manual collection

- $\quad$ Ease of use

- Cheap and quick process 


\section{- $\quad$ Real-time monitoring.}

\section{LITERATURE REVIEW}

Literature review is the study to be done to gain knowledge and skill needed to complete the survey. This is done to get help in the completion of a project. It is a survey on the previously existing material on the topic of our interest. The main aim of the literature review to develop and improve a successful project.

Some of the previously published paper which are studied for implementation of the system are mentioned below:

[1] Kalpana, M. B., and M. Tech Student. "Online monitoring of water quality using raspberry Pi3 model B." The main aim of the proposed paper is to automatically monitor the quality of water. The model is used to calculate the input value and update the data into the server without the work done by a human. The system is based on raspberry $\mathrm{Pi} 3$ model B to get the data from different sensors used in the project over the internet. The model is efficient, convenient, and fast for monitoring the water. The system is flexible for any sensor used in the system and coding is done in python programming. The system can be used in various applications and with extension value. It can be used to monitor other values like hydrologic, air pollution, industrial and agricultural production, and so on.

[2] Chandanapalli, Suresh Babu, E. Sreenivasa Reddy, and D. Rajya Lakshmi. "Design and deployment of aqua monitoring system using wireless sensor networks and IARKick." The system is based on hardware components and forms a wireless sensor network for aquaculture monitoring, with different sensors and transmitter/ receiver and contain software design. The system contains two models that are transmitter station and a second is receiver station. The transmitter station contains all the sensors, microcontroller, and GSM, analog/ digital converter. The receiver station contains a GSM module which is used for receiving the data capture by the sensor through the transmitter in the GSM network. The receiver station is used to receive the data and store it into the database for further calculation and observation. Visualization and analysis of data are done then the notification is sent to the farmer on mobile phone and alerts them when changes occur in environmental condition.

[3] Daigavane, Vaishnavi V., and M. A. Gaikwad. "Water quality monitoring system based on IoT." The system is based on IoT and is low-cost real-time monitoring of water. The system consists of various sensors to calculate the required value for monitoring the nature of water and connected to Arduino. The sensor data is viewed on a wi-fi system over the internet. Later, the data is sent to the BLYNK app for visualization, and data is shown through different widgets and an alert message is sent to the owner.

[4] Kaimal A, Jaison R, Santha V, Anand S, "Smart Aquarium". The project deals with the monitoring of $\mathrm{pH}$, level of water, temperature, and feeding the fish of the aquarium. The system is made of PLC (Programmable Logic Controller) and SCADA (Supervisory Control and Data Acquisition) for the automatic control and monitoring of different parameters of the aquarium. The project can be implemented further to be used on large scale. This smart aquarium will save time and the owner need not to worried when he is not home. As PLC is used as the controller, different aquariums can be connected and used using a single PLC.

[5] Mohd Saad Hamid, Muhammad Amirul Abd Wahab, Rasyidah Abdullah, "Development of Water Quality Monitoring for Smart Aquaculture System", project mainly focuses on local aquaculture species and allow the fish farmer to monitor the water quality and condition of fish. The system is build using Raspberry pi with different sensors for monitoring the relevant values for monitoring the water quality. The system is used for early detection as connected to the BLYNK cloud for sending and storage of data. The visualization of calculated data is done in the BLYNK platform, as it provides its server and cloud for storage, and notification is sent to the farmer when some changes occur like water.

[6] Pasika, Sathish, and Sai Teja Gandla. "Smart water quality monitoring system with cost-effective using IoT", discussed the design of a system that is efficient, costeffective, can work in real-time. The main aim of the system is to find the drinking water is safe for health or not through water quality monitoring with the help of the Internet of Things. In this model microcontroller unit (MCU) is used to connect the required sensor for monitoring the nature of water and further processing is done in a web app. ThingSpeak platform is used for the analysis and visualization of data. The platform provides its server and cloud for storage of data and have lots of functionalities and graphically show the result through MATLAB programming and sent the data over the IoT.

[7] Miry, Abbas Hussien, and Gregor Alexander Aramice. "Water monitoring and analytic based ThingSpeak." The main aim of the proposed system is to convey the advantages of real-time monitoring over the traditional method of water quality. The system is built on IoT over the internet to monitor the quality of water for different places. The system uses a hardware component and is programmed in Arduino IDE and used ThingSpeak platform for observation and visualization of data. The ThingSpeak platform will provide a ThingSpeak server and cloud which is used for storage and analysis of data. The calculated values can be observed using the web application and mobile application of the ThingSpeak platform, and an alert message is sent to notify about the condition of the water. The proposed model can also use in other fields like healthcare etc.

[8] Junaid Khan, Onib-Ur-Rehman, Zafran Jalil1, Sikandar Ali, Abdul Samad Danish, "Implementation of Smart Aquarium System Supporting Remote Monitoring andControlling of Functions using Internet of Things". the system discussed the fully automated and remote monitoring of the aquarium. An important feature of the project includes mechanical design of fish feeding system, real-time monitoring of the feeding, observation of other parameters like $\mathrm{pH}$ value, temperature, turbidity, the water level of the aquarium. The results can be observer through the web app or mobile app on a smartphone. The system is build using Node MCU v1.0, Cayenne, and Arduino mega 2560 for sending the data over the IoT with the aid of the internet. The system is designed to automatically take care of the fish and to remotely control the device over the cloud. The system design a new mechanical fish feeder which is efficient and saves time for humans and can automatically take care of the 
fish and real-time monitoring is done, also cost-effective and easy to use.

\section{INTERNET OF THINGS}

The Internet of Things (IoT) is a large network that connects different objects over the internet. It refers to a system of interconnected objects that are connected to collect and transfer data over the internet without human need. IoT can build a system which is automatic, efficient, effective and essential for all human being. IoT comprises lots of applications, it includes innovative shopping, system infrastructure management, remote health monitoring, emergency notification system.

The Internet of Things (IoT) is a communication model of present-time which connects different objects like microcontroller, digital transmitter, receiver over the internet for communication purposes and perform various functions. The main aim of IoT to make the internet famous for easy interlinkage with a large number of devices like home automation, surveillance devices, engine, vehicles, etc. due to the tremendous increase in the IoT, many other platforms also connect with a heterogenous object over the internet.

Characteristics of IoT system:

1. IoT system consists of a central object which has unique identification to be easily distinguished from the other objectives of the network.

2. The object of the IoT system should be able to detect the existence of other objects that appears in the network.

3. The object of IoT (sensor) should able to capture the data automatically.

4. The object must be interpretational within different communication technologies.

5. There should be service-based interaction between objects. IoT systems should have low power operations and they should be secure.

\section{METhODOLOGY}

The proposed model is an embedded system with hardware and software parts. As the embedded system is a microprocessor-based is the combination of hardware system with software programming. The system is based on IoT (Internet of Things) for designing an advance and effective water quality monitoring system. The system consists of required sensors for collecting the environment data and sending it to a further layer where the observation of the data is done and sends the result to the ThingSpeak server.

The embedded system is the main key of the system which includes NodeMCU as a Wi-Fi module. The main component of the system which is responsible to connect all the hardware component to the software part. The Wi-Fi module is used with a $3.3 \mathrm{v} / 5 \mathrm{v}$ power supply. Here we are using a total of 3 sensors for capturing the relevant important data, like $\mathrm{pH}$ sensor, temperature sensor, turbidity sensor, each of the sensor can operate on a $3.3 \mathrm{v} / 5 \mathrm{v}$ power supply and input pin and ground pin which is connected to NodeMCU's ground pin and Analog pin. Then sensors after connecting start collecting the input data and send it for further visualization.
Coding of the sensors and NodeMCU is done in Arduino IDE after setting up the required board and ports. Coding is done in embedded $\mathrm{C}$ language which is easy to understand and use. The ThingSpeak platform will be used for visualization of the results, as in the ThingSpeak new channel is created and setting of all the widgets is done according to the requirements and it will provide an API key which is used to connect the ThingSpeak to the NodeMCU. We just need to write the code in Arduino IDE for all the sensor and connect the code with the ThingSpeak server by providing the API key in the codes and upload it. ThingSpeak will show the output as results which is collected by sensors as input data. In the later part, IFTTT applets are used to send the notification when the sensor detects some changes in the surroundings and exceeds the thresholds which may be dangerous for the aquatic life.

\section{SySTEM ARCHITECTURE LAYER}

The architecture consists of three layers, shown in fig 1 . They are:

\section{A. Perception Layer}

The perception layer is the physical layer of the IoT. It is the first layer of architecture which includes all the sensor which will be used in the respective system. In this layer, different sensors which are used in the system will gather the input data and collect the value of our area of interest and upload it to the next layer for further observation.

\section{B. Network Layer}

Network Layer is used for connecting all the devices and accept the data which is collected by different sensors present in the perception layer. This layer's main aim to transmit and process sensor data. The network layer forms the middle layer that is responsible for connecting the whole system.

\section{Application Layer}

The application Layer is the top-most layer of the IoT architecture which is responsible for storage, analysis, visualization of the data. The application layer is responsible for conveying various services to the user. It provides lots of features that have great importance in the Internet of Things for connecting various objects.

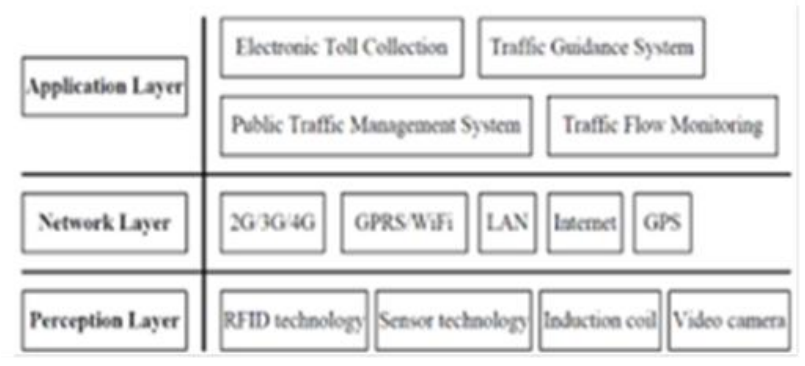

Fig. 1. System Architecture layer

\section{HARDWARE COMPONENT}

\section{A. pH Sensor}

In chemistry, $\mathrm{pH}$ is known as 'potential of hydrogen' or 'power of hydrogen'. It is a scale that is used to specify whether the solution is acidic or basic. A pH scale is logarithmic and the concentration of hydrogen ions in a 
solution. The $\mathrm{pH}$ ranges from 0 to 14 . There are three types of solution present in nature, at $250 \mathrm{C}$ if the $\mathrm{pH}$ of the solution is less than 7 then the solution is 'acidic' and greater than that are basic. Solution of $\mathrm{pH}$ equal to 7 is known as neutral. The $\mathrm{pH}$ ranges from 6.5 to 9.5 are safe for drinking and also healthy for aquatic species. So, a $\mathrm{pH}$ sensor, fig 2 . is used to measure the $\mathrm{pH}$ value of water in the planted tank to get detailed information about the quality and feature of water and to decide whether is safe or not and when the values exceed the threshold there is a need to change the water of the tank.

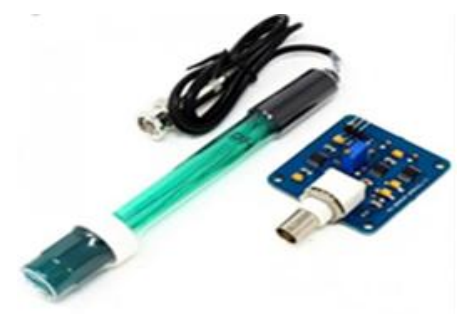

Fig. 2. pH Sensor

\section{B. Turbidity Sensor}

The Turbidity sensor, fig 3. measures the water clearness, i.e., the total number of particles suspended on the water. A turbidity sensor is used to compute the quantity of light that is disintegrated by the suspended solids in water and calculate the number of water particles floating in the water. Exceeds in turbidity may harm the aquatic species and cause illness to fishes. As the amount of total suspended solids (TSS) in water increases, the turbidity level of water also increases. The turbidity sensor measures the changes in the water quality and shows the results, if the range exceeds the safe level the water needs to be the change of healthy life of aquatic species in the planted tank.

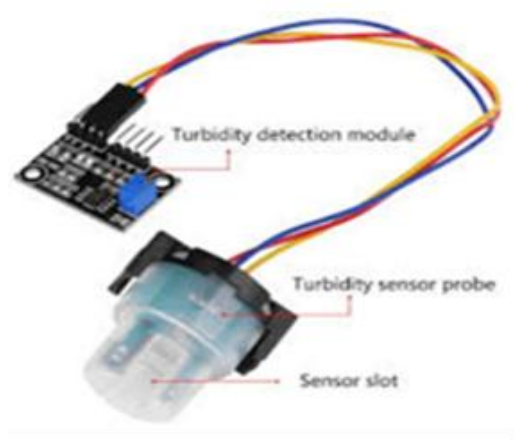

Fig. 3. Turbidity Sensor

\section{Temperature Sensor}

A Temperature sensor, fig 4 . is used to detect the temperature of water i.e.; water is hot or cold. The range of the DS18B20 temperature sensor is -55 to $+125{ }^{\circ} \mathrm{C}$. This temperature sensor gives accurate reading as it is a digital type sensor. DTH-11 sensor is also used to measure the temperature and humidity of the atmosphere. This sensor has a negative temperature coefficient (NTC) component for measurement of temperature, and it is connected to a high high-performance 8-bit microcontroller, which provides excellent quality, fast response, anti-interference ability, and cost-effectiveness. This sensor is used to measure the temperature of the surroundings and to check that the $\mathrm{pH}$ and turbidity sensors are worked correctly over a long time.

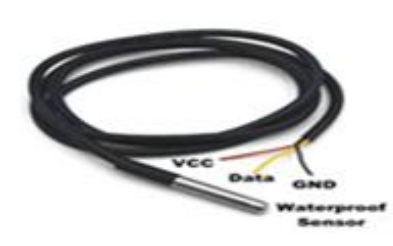

Fig. 4. Temperature Sensor

\section{NodeMCU}

Node Micro Controller Unit (NodeMCU), fig 5. is an open-source IoT platform. NodeMCU runs on ESP8266 WiFi SoC. It is a Wi-Fi module that is used to connecting all the sensors with the IoT. It is a hardware and software developing environment. Coding of the NodeMCU is done in Arduino IDE after setting up the required board and ports. Power is supply through USB cable. NodeMCU comes with multiple ports, feature, and specification.

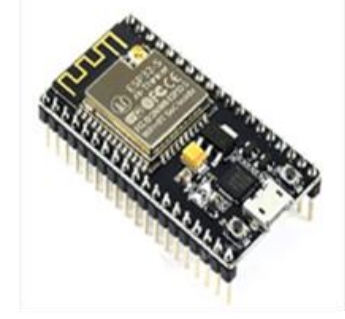

Fig. 5. NodeMCU

\section{SOFTWARE COMPONENT}

\section{A. Arduino IDE}

The Arduino Integrated Development Environment (IDE) is multiple computing platforms and works for Windows, Mac OS, Linux. This platform allow us to do programming for all the sensors of the area of interest of the project and uploading it to the microcontroller used. The Arduino IDE supports Embedded $\mathrm{C}$ for coding for all the hardware equipment and uses the special rule of code structuring. Arduino IDE supplies in-build program for different microcontroller and supplies software library from the wiring project, provide input and output procedures.

\section{B. ThingSpeak Server}

ThingSpeak is an open-source Internet of Things (IoT) analytics platform that provides various functionalities like, aggregate, and analyse live data steam, storage of data in the cloud, and visualization of data through MATLAB programming. ThingSpeak server, fig 6. main functionality is to collect the input data measure by the sensors and upload the data privately into the cloud. After that analyse and visualize your data with MATLAB, and graphically show the result. We can also add different widgets of our interest and perform different tasks in it by adding react and action, then the server will trigger a reaction.

ThingSpeak Features

- Collect data in private channels

- Share data with public channels 
- $\quad$ RESTful and MQTT APIs

- MATLAB analytics and visualizations

- $\quad$ Event scheduling

- Alerts

- App integrations

Works With

- MATLAB

- Arduino

- Particle Photon and Electron

- ESP8266 Wi-Fi Module

- Raspberry Pi

- LoRaWAN

- Things Network

- $\quad$ Senet

- Libelium

- Beckhoff

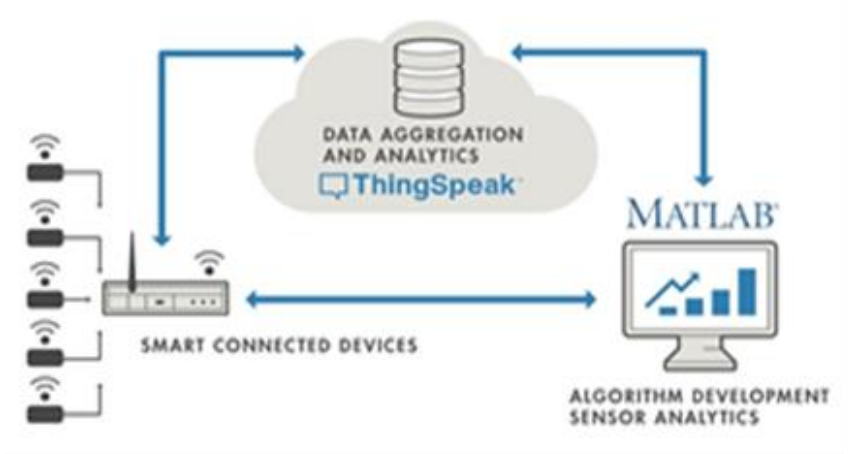

Fig. 6. ThingSpeak

\section{IFTTT applets}

If this then that commonly known as IFTTT, fig 7. is a service that is used to program various responses for events of different kinds. Multiple events are present to which IFTTT can respond via the internet. IFTTT is used to send the notification if the threshold meets. Webhooks is one of the functionalities of IFTTT which is used for automatic calls to a server. If the specific event happens then that call will trigger. IFTTT is a cloud application in which webhook is a method in web development that is responsible for changing the behavior of the web pages and web application. Webhooks are user-defined HTTP callbacks. They are usually triggered by some event, such as when the value meets the threshold, or a comment is posted on a blog, or any spam detected, etc. When the event occurs, the source site makes an HTTP request to the URL for the webhook. Users can arrange them to form events on one site to cite behavior on another side. Webhooks use HTTP, which can be integrated into web services without adding new infrastructure. architecture which is responsible for storage, analysis, visualization of the data. The application layer is responsible for conveying various services to the user. It provides lots of features that have great importance in the Internet of Things for connecting various objects.

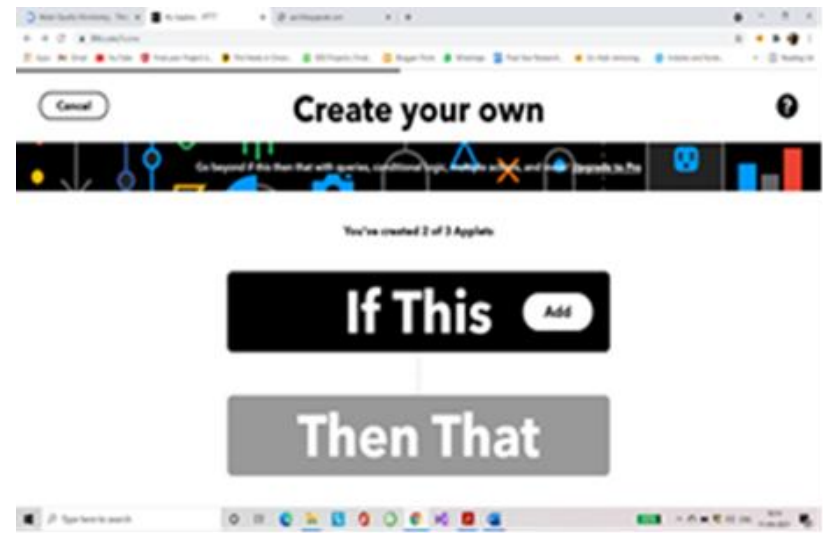

Fig. 7. IFTTT

\section{AlgorithM OF PROPOSED SYSTEM}

The proposed system algorithm is shown in the Fig 8 bellow. At first, the initialization of required sensors is done and connected with NodeMCU which is used to connect all the sensors with it and over the internet to perform various functionality. $\mathrm{Ph}$ sensor is used to observe the $\mathrm{pH}$ value of water in the planted tank, turbidity sensor will observe the clearness of the water and the amount of light scattered into the water, and temperature sensor will calculate the temperature and humidity of the surroundings to observe the proper functioning of $\mathrm{pH}$ sensor and turbidity sensor. ThingSpeak server is initialized by logging into the website and creating a channel in it for water quality monitoring. Further need to sign in into IFTTT webhooks for getting the notification about the situation of the planted tank to the owner.

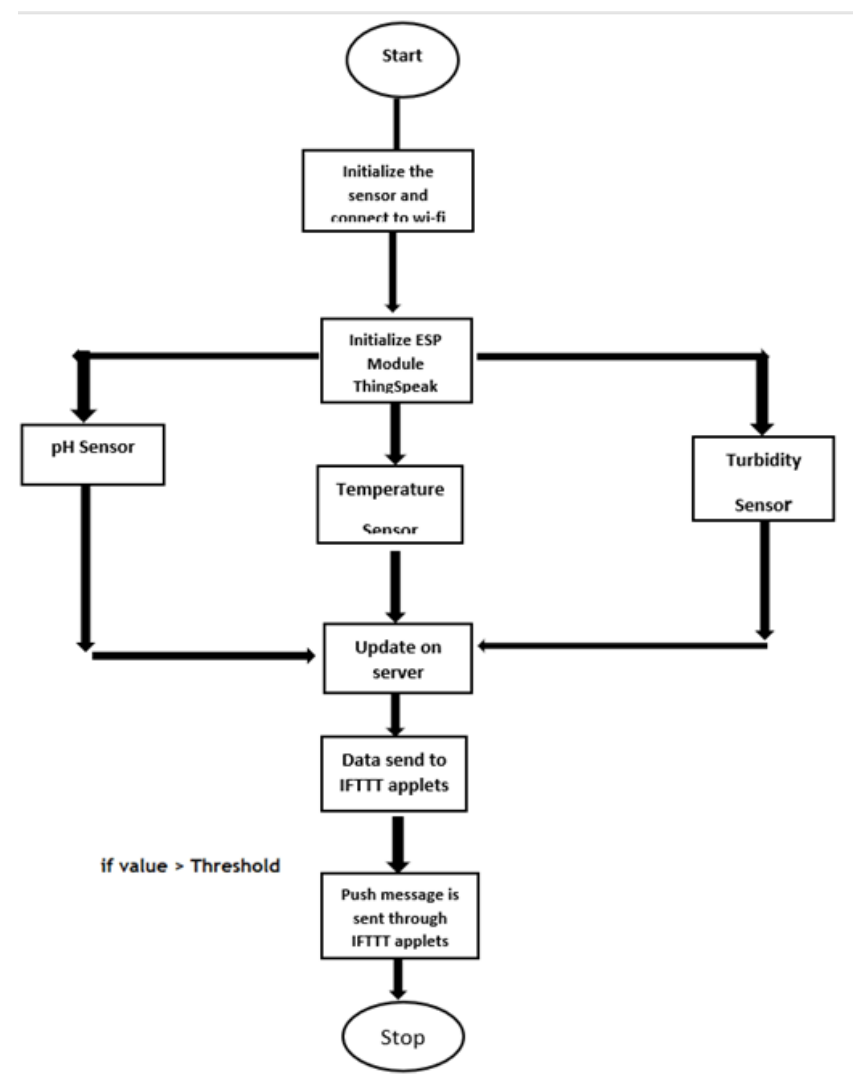

Fig. 8. Algorithm for the proposed system. 
The implementation of the system is composed of two parts, hardware, and software. Firstly, setting of all hardware parts is done like, $\mathrm{pH}$ sensor, turbidity sensor, and temperature sensor are connected with NodeMCU, shown in fig 9. Then we will move toward the software implementation as coding of all the sensors is done in Arduino IDE in embedded $C$ language. After that creating a channel in the ThingSpeak server and adding all the required widgets. Then ThingSpeak server is connected with the code by writing the write API key of the channel into it. As the power supply is given to the hardware component and dipped into the planted tank, all the sensors start calculating the values according to the codes and then upload them into the ThingSpeak server and its cloud. The data get updated as the new value is observed by the sensor. The data visualization is done through MATLAB programming in ThingSpeak and graphically shows the results. The results are also shown in decimal and gauge form by setting the widgets accordingly.

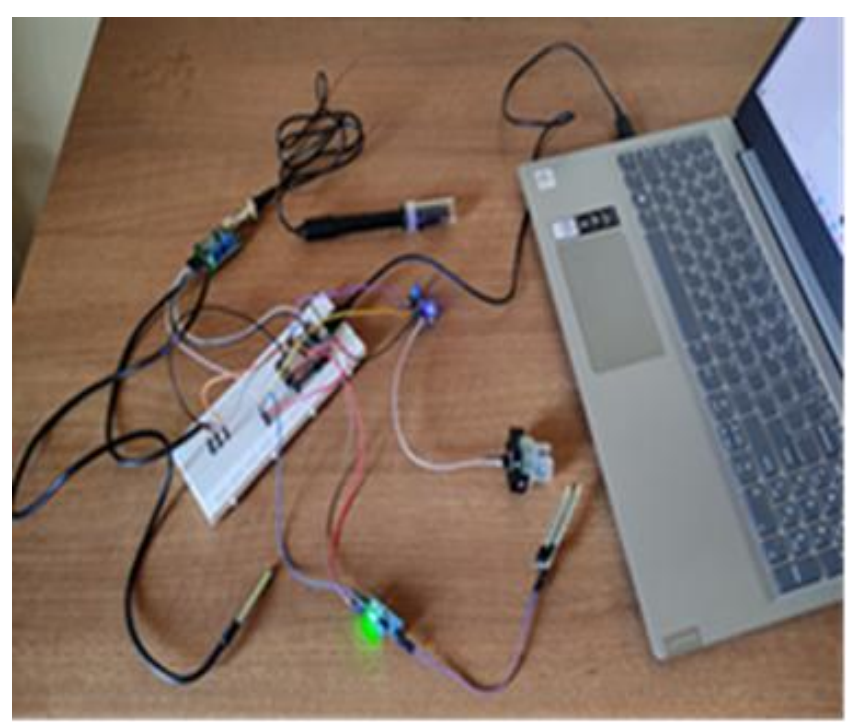

Fig. 9. Hardware Configuration

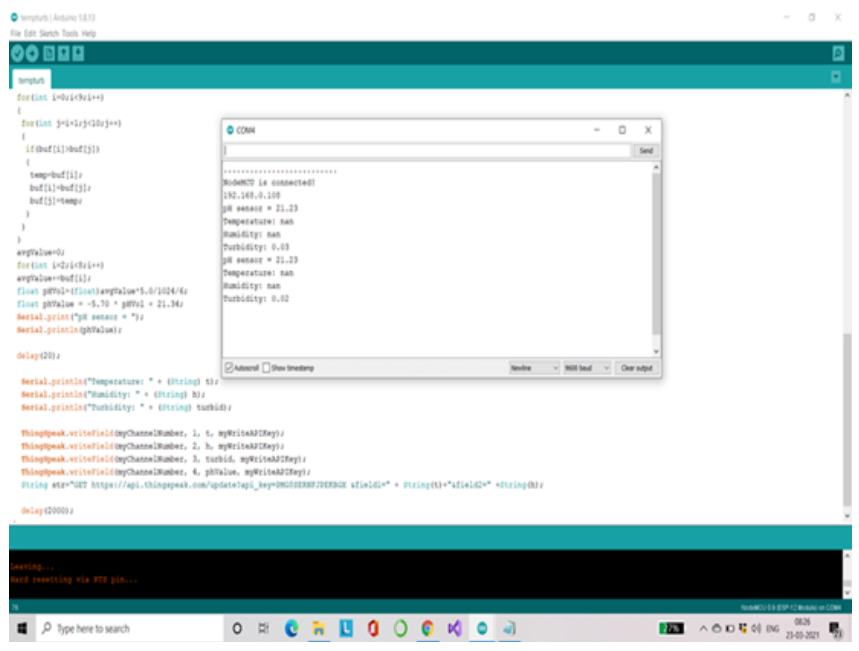

Fig. 10. Results in Arduino IDE

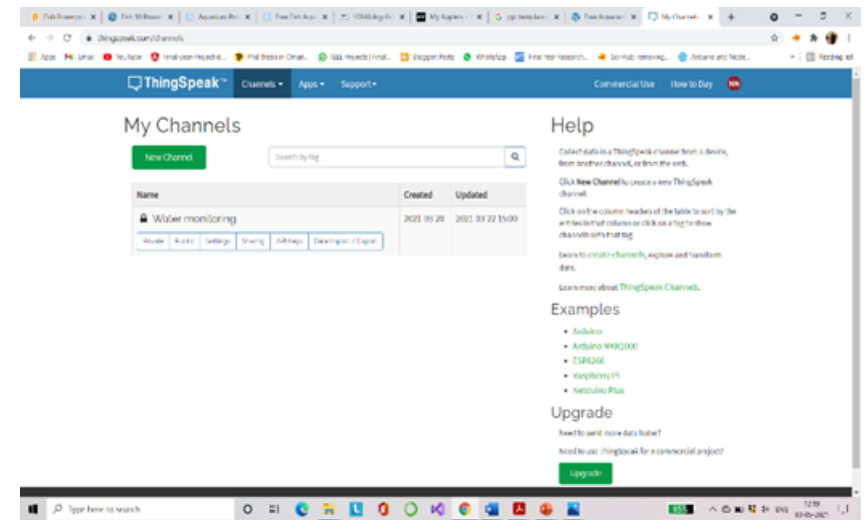

Fig. 11. Channel in ThingSpeak

In the last phase of the system, the ThingSpeak server is connected to IFTTT, by logging in to it. IFTTT is a web application which provides multiple functionalities for which ThingSpeak services are used like ThingHTTP and ThingSpeak react It uses the IFTTT webhooks services to create web request which will trigger an action like SMS, Email, Gmail, call when the threshold meet. There is an HTTP request to a web server as an incoming action and sending of e-mail or SMS will be the outgoing action. Firstly, IFTTT applets are created, to activate the event on IFTTT, the URL of IFTTT is used in ThingHTTP. Then ThingSpeak React application is used to interact with the senor for reading the values and checking the threshold and as the threshold meets or exceeds it will through a message to the registered email or mobile number informing about the situation, whether the temperature exceeds or $\mathrm{pH}$ exceeds.

\section{RESUlTS AND DisCUSSION}

The result of our work can be shown in a curve that is generated in the ThingSpeak, fig 12. that is calculated and monitored from a different sensor like $\mathrm{pH}$, turbidity, and temperature sensor and uploaded in it. Different curves and widgets are used to show the results of different sensors respectively. The curve is made as the sensors calculate the input data for different dates and times. Also used ThingSpeak mobile app, fig 13. for getting the results of the sensor in mobile phones, fig 14. Then IFTTT applets within the webhook services and the services provided by ThingSpeak like ThingHTTP and ThingSpeak React by using the URL of IFTTT applets to send the notification or push message to the owner's registered number, shown in fig 15.

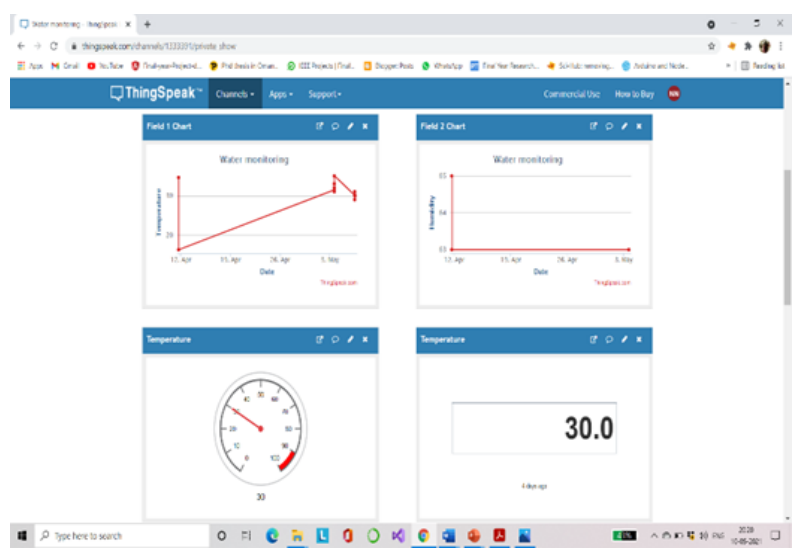

Fig. 12. Results in ThingSpeak 


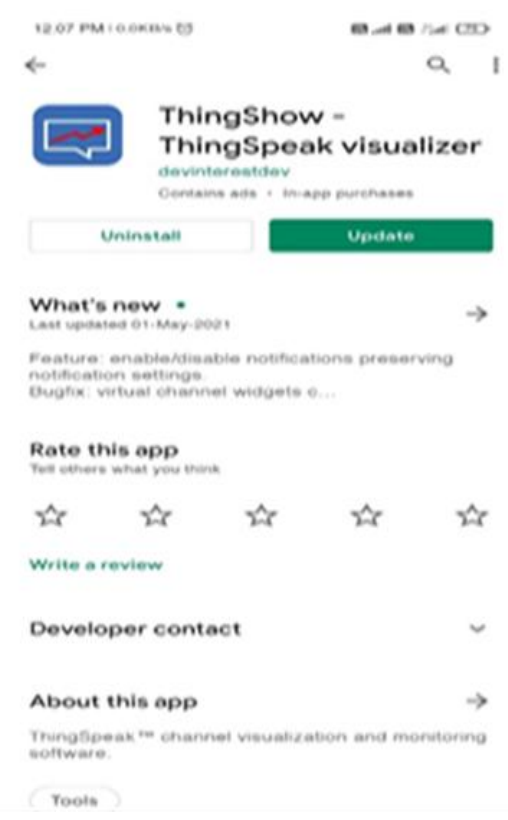

Fig. 13. ThingSpeak app installation.

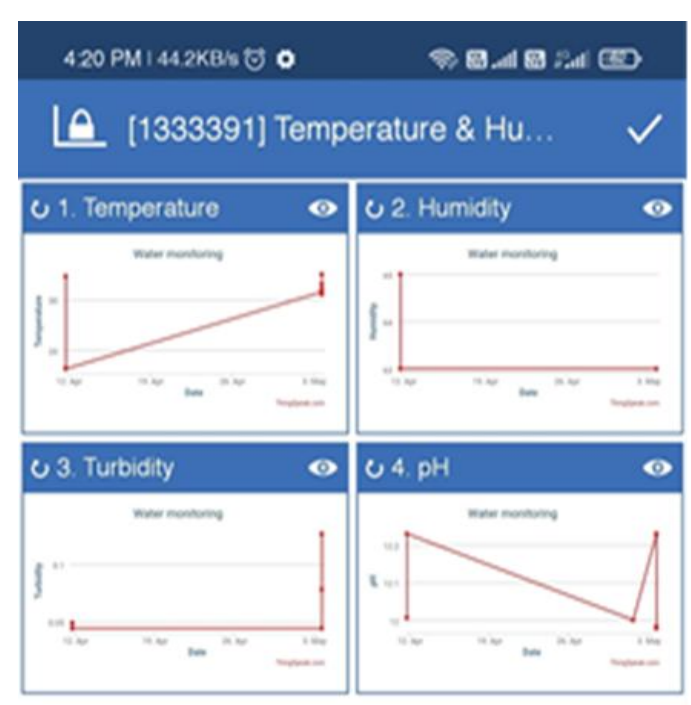

Fig. 14. Results in ThingSpeak mobile App
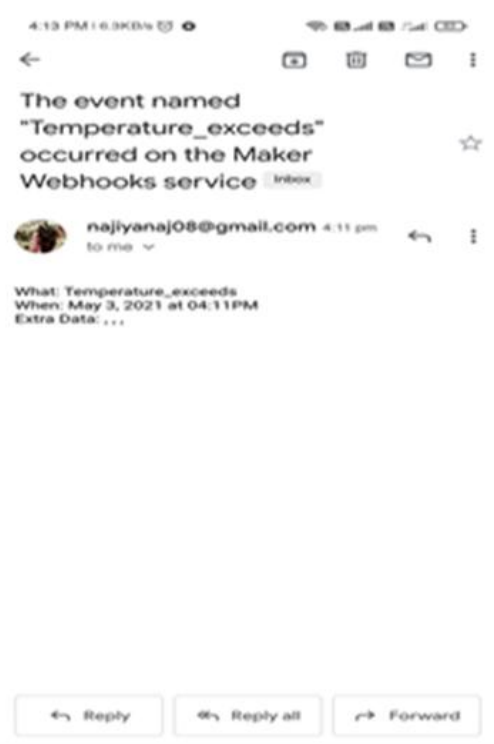

Fig. 15. Notification from IFTTT

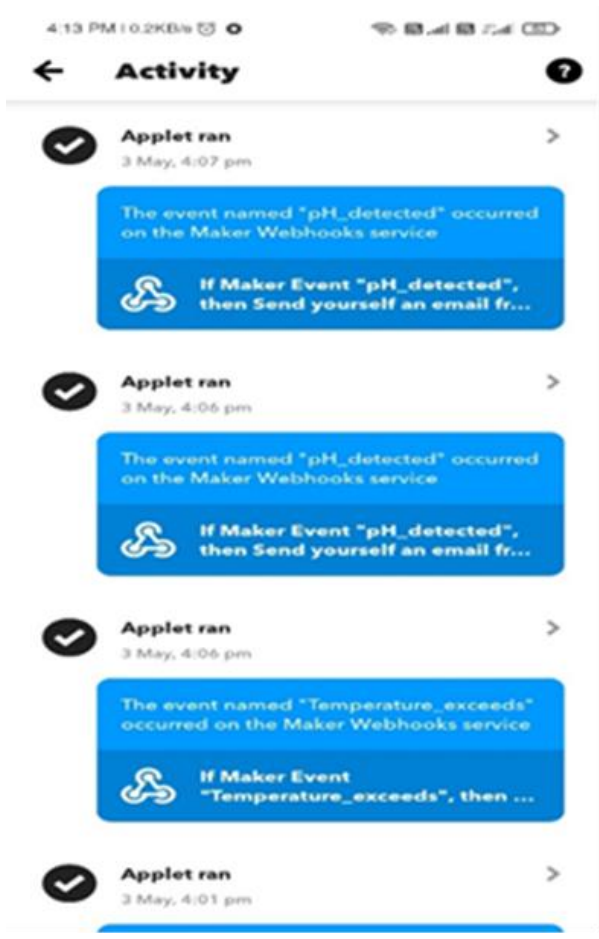

Fig. 16. Results from IFTTT

\section{CONCLUSION}

The proposed system's main aim to implement smart water quality monitoring in a planted tank. This system will check the quality and features of water in real-time. As the monitoring of water quality is an important factor to keep the life of aquatic plants and animals healthy and safe. The system in this paper is a cost-effective and efficient model for real-time monitoring of water. ThingSpeak which is a web application is used for monitoring and visualization of the results calculated by the different sensors used in the system and upload them to the ThingSpeak server. Further, the value can also monitor in ThingSpeak mobile application. Later, IFTTT applets come into the picture, which uses the services provided by ThingSpeak like ThingHTTP and ThingSpeak Reacts. As ThingSpeak service uses the URL of IFTTT applets and then it will notify the owner when the calculated values increase the threshold.

\section{ACKNOWLEDGMENT}

The authors wish to thank Mr. Dr. Nilesh B. Fal Dessai (H.O.D, Information Technology, and Engineering) who inspired us with his valuable suggestions and providing all the facilities in completing the project work.

We shall remain grateful to the Principal of GEC for proving us with a strong academic atmosphere by enforcing strict discipline to do the project work with utmost concentration and dedication.

I want to thank my family and friends for showing their great help and support and providing generous love and care throughout life and the entire period to complete the project.

\section{REFERENCE}

[1] Kalpana, M. B., and M. Tech Student. "Online monitoring of water quality using raspberry Pi3 model B." International Journal of Innovative Technology and Research 4.6 (2016): 4790-4795. 
[2] Chandanapalli, Suresh Babu, E. Sreenivasa Reddy, and D. Rajya Lakshmi. "Design and deployment of aqua monitoring system using wireless sensor networks and IAR-Kick." Journal of Aquaculture Research and Development 5.7 (2014).

[3] Daigavane, Vaishnavi V., and M. A. Gaikwad. "Water quality monitoring system based on IoT." Department Electronics \& Telecommunication Engineering, Advances in Wireless and Mobile Communications 10.5 (2017): 1107-1116.

[4] Kaimal A, Jaison R, Santha V, Anand S, "Smart Aquarium", National Conference on "Emerging Research Trends in Electrical, Electronics \& Instrumentation", (ERTEEI'17).

[5] Mohd Saad Hamid, Muhammad Amirul Abd Wahab, Rasyidah Abdullah, "Development of Water Quality Monitoring for Smart Aquaculture System", Journal of Engineering and Applied Science 14 (9); 2840-2847, 2019.

[6] Pasika, Sathish, and Sai Teja Gandla. "Smart water quality monitoring system with cost-effective using IoT." Heliyon 6.7 (2020): e04096.

[7] Miry, Abbas Hussien, and Gregor Alexander Aramice. "Water monitoring and analytic based ThingSpeak." International Journal of Electrical and Computer Engineering 10.4 (2020): 3588.

[8] Junaid Khan, Onib-Ur-Rehman, Zafran Jalil1, Sikandar Ali, Abdul Samad Danish, "Implementation of Smart Aquarium System Supporting Remote Monitoring and Controlling of Functions using Internet of Things", Journal of Multidisciplinary Approaches in Science Volume 9, Issue 1 (2019) 9-28.

[9] Simbeye, Daudi S., and Shi Feng Yang. "Water quality monitoring and control for aquaculture based on wireless sensor networks." Journal of networks 9.4 (2014): 840.

[10] Amrita, C. Mercy, and D. Babiyola. "Analysing the water quality parameters from traditional to modern methods in aquaculture." International Journal of Science, Environment and Technology 7.6 (2018): 1954-1961.

[11] Methongjan, Kittikhun, and Suwit Kongsong. "Aquarium fish smart farming on internet of things (IoT) and mobile application technology." International Academic Multidisciplinary Research Conference in Amsterdam 2019.

[12] Lin, Yi-Bing, and Hung-Chun Tseng. "FishTalk: An IoT-based mini aquarium system." IEEE Access 7 (2019): 35457-35469.

[13] Chowdury, Mohammad Salah Uddin, et al. "IoT based real-time river water quality monitoring system." Procedia Computer Science 155 (2019): 161-168.

[14] Ramya, A., R. Rohini, and S. Ravi. "Iot based smart monitoring system for fish farming." International Journal of Engineering and Advanced Technology 8.6 Special Issue (2019): 420-424.

[15] Bokingkito Jr, Paul B., and Orven E. Llantos. "Design and implementation of real-time mobile-based water temperature monitoring system." Procedia Computer Science 124 (2017): 698705.

[16] Patel, Shweta, et al. "SMART FISH TANK USING IOT." Special Issue 11 || ICCEME 2019-2020 || ISSN (Online) 2456-0774.

[17] Hardyanto, R. Hafid, Prahenusa Wahyu Ciptadi, and Andik Asmara. "Smart Aquarium Based On Internet of Things." Journal of Business and Information Systems (e-ISSN: 2685-2543) 1.1 (2019): 48-53.
[18] Daud, Ahmad Kamal Pasha Mohd, et al. "An IoT-Based Smart Aquarium Monitoring System." 2020 IEEE 10th Symposium on Computer Applications \& Industrial Electronics (ISCAIE). IEEE, 2020.

[19] Huan, Juan, et al. "Design of water quality monitoring system for aquaculture ponds based on NB-IoT." Aquacultural Engineering 90 (2020): 102088 .

[20] Premalatha, Y., and A. P. Lipton. "Water quality management in gold fish (Carassius auratus) rearing tanks using different filter materials." Indian Hydrobiology 10.2 (2007): 301-306.

[21] Ramesh, Maneesha V., et al. "Water quality monitoring and waste management using IoT." 2017 IEEE Global Humanitarian Technology Conference (GHTC). IEEE, 2017.

[22] Encinas, Cesar, et al. "Design and implementation of a distributed IoT system for the monitoring of water quality in aquaculture." 2017 Wireless Telecommunications Symposium (WTS). IEEE, 2017.

[23] Daud, Ahmad Kamal Pasha Mohd, et al. "An IoT-Based Smart Aquarium Monitoring System." 2020 IEEE 10th Symposium on Computer Applications \& Industrial Electronics (ISCAIE). IEEE, 2020.

[24] Zailani, Mohd Faiz Bukhari Bin Othman. "Evelopment of smart fish farming using IoT Using Wasted Warm Water Energy." (2018): 155163.

[25] Ramya, A., R. Rohini, and S. Ravi. "Iot based smart monitoring system for fish farming." International Journal of Engineering and Advanced Technology 8.6 Special Issue (2019): 420-424.

[26] Balakrishnan, S., S. Sheeba Rani, and K. C. Ramya. "Design and development of IoT based smart aquaculture system in a cloud environment." International Journal of Oceans and Oceanography 13.1 (2019): 121-127.

[27] Odema, Mohanad, et al. "Smart aquaponics system for industrial Internet of Things (IIoT)." International Conference on Advanced Intelligent Systems and Informatics. Springer, Cham, 2017.

[28] Elsokah, Moeid M., and Malek Sakah. "Next generation of smart aquaponics with internet of things solutions." 2019 19th International Conference on Sciences and Techniques of Automatic Control and Computer Engineering (STA). IEEE, 2019.

[29] Boonrawd, Patcharapol, Siranee Nuchitprasitchai, and Yuenyong Nilsiam. "Aquaponics Systems Using Internet of Things." International Conference on Computing and Information Technology. Springer, Cham, 2020.

[30] Kim, Yuhwan, et al. "Realization of IoT based fish farm control using mobile app." 2018 International Symposium on Computer, Consumer and Control (IS3C). IEEE, 2018.

[31] Balakrishnan, S., S. Sheeba Rani, and K. C. Ramya. "Design and development of IoT based smart aquaculture system in a cloud environment." International Journal of Oceans and Oceanography 13.1 (2019): 121-127.

[32] $\mathrm{Hu}$, Zhuhua, et al. "A method overview in smart aquaculture." Environmental Monitoring and Assessment 192.8 (2020): 1-25.

[33] Dzulqornain, Muhammad Iskandar, M. Udin Harun Al Rasyid, and Sritrusta Sukaridhoto. "Design and development of smart aquaculture system based on IFTTT model and cloud integration." MATEC Web of Conferences. Vol. 164. EDP Sciences, 2018. 